\title{
Editorial: open access journals' situation and future
}

\section{Editorial}

Materials Science and Engineering International Journal, MSEIJ, has been running seven years. As we look back the past years, we are proud that the journal has continuously and stably published papers. It is not taken for granted that it easy to achieve such a success because not every new journal can accomplish this kind of achievement. Some journals maybe publish very few articles and issues are always in irregular cycle. For a brand new journal, the growth is hard, even though the publishing methods have undergone great change today. The open access $(\mathrm{OA})$ is popularly applied. The electronic publishing has been the most popular way instead of the traditional print journals. The response for publishing is much faster and convenient. However, credits need to be accumulated step by step. On the other hand, there are also fierce competition in publishing sector. The new publishing method brings great opportunities and challenges as well. The opportunities can be seen by others, so there is competition. Then how to survive and become a winner is a serious topic. In recent years, many OA journals appear, for example, Elsevier group's 2,650 journals now enable open access publishing, including 500 fully OA journals. In 2020, Elsevier published 81,000 gold or pay-to-publish OA articles, an increase of $65 \%$ over $2019 .{ }^{1}$ There are 135 OA journals related to materials science and 33 about metals and alloys regardless of journals about specific materials. ${ }^{2}$ Many subscription journals are transforming into OA mode, called hybrid OA journals. And new OA journals are still emerging every year. I believe many academic scientists get emails almost every week from new journals which are advertising and ask for submission of articles. Preprint is also a new method for open access, which means the articles have not yet been peer reviewed or published in a journal. Thus, it is assured that many new OA journals have been in the dilemma of lack of submissions for long time. However, tons of papers are rejected by noted journals. For example, Materials and Design accepted 939 from 4782 articles with a low acceptation rate of $19.6 \%$ in $2020 .{ }^{3}$ Why does this phenomena happen? The traditional journals build their impact, credits and gain great advantages during their years of running. One of their impacts in the research area is the citation index, for example, SCI, EI, Scopus, etc. These means the article published in these journals will be read widely and be cited widely. The citation is another index for the article quality and academic contribution. But for a new journal, that is a high threshold. Thus, there are doomed to go a long way to achieve the same success. Does that mean there is no future for the new OA journals? The answer is definitely no. Innovative measures should be taken as follows.

High quality, say no to low quality articles. The quality is always the keystone of a journal. It can't be lowered or deducted even though there is the trouble of lack of article submissions. Quality discount will be harmful for the journal and the situation will get into a negative cycle of poor quality-less submission. Even an issue cannot be published normally or on time, poor quality articles should be rejected without hesitation. Cooperation with successful and noted journals. Establish good cooperation with them will earn a great source of submissions. Usually, a lot of papers are diverted to sister journals. And they will serve as models for new journals and be beneficial for the establishment of reputation and impression. Fast review. This is

\author{
Volume 5 Issue 3 - 202I
}

Jinwu Kang
Tsinghua University, China

Correspondence: Jinwu Kang, School of Materials Science and Engineering, Key Laboratory for Advanced Materials Processing Technology, Tsinghua University, Beijing 100084, China, Email kangjw@tsinghua.edu.cn

Received: May 29, 2021 | Published: June 02, 2021

another important factor. Review time for subscription journals is usually months long or even years long, which spoils the appetite of scientist because of the fast development of science and technology requires efficiency and in time communication. If the results after review is minor or even major revision, it is fine. But if it is rejection, that means a lot of time is wasted, resulting into a big delay. So, fast review and fast results are attractive, which provides authors more freedom for the transfer from a journal to another. Impact and index effect. A new journal has to take participate into the citation index systems, which means they should join the journals' club. Then, their influence will be fast established.

Innovative methods have to be taken. Business breakthrough maybe change the academic publishing area. In OA area, there are models of gold $\mathrm{OA}$ and green $\mathrm{OA}$ to treat the article processing charge (APC). In recent years, Diamond Open Access (DOA) model was proposed, ${ }^{4}$ which means authors publish their articles in openaccess journals and books without paying any processing and/ or publication fee, meanwhile, readers are not required to pay any cost to publisher for reading these articles. That is very attractive. IT technology, artificial intelligence and etc. are bringing more and more techniques and new ideas to research and every sector of our life. These technologies are also possible for publication. I believe there will be new models and new breakthrough in publishing sector, which brings new opportunities for OA journals, including MSEIJ.

\section{Acknowledgments}

None.

\section{Conflicts of interest}

The author declare that there is no conflict of interest.

\section{References}

1. https://www.elsevier.com/open-access

2. https://www.scimagojr.com/

3. https://journalinsights.elsevier.com/journals/0264-1275/acceptance_rate

4. https://www.iaamonline.org/blog/celebrating-10th-years-of-diamondopen-access-publishing-in-advanced-materials 